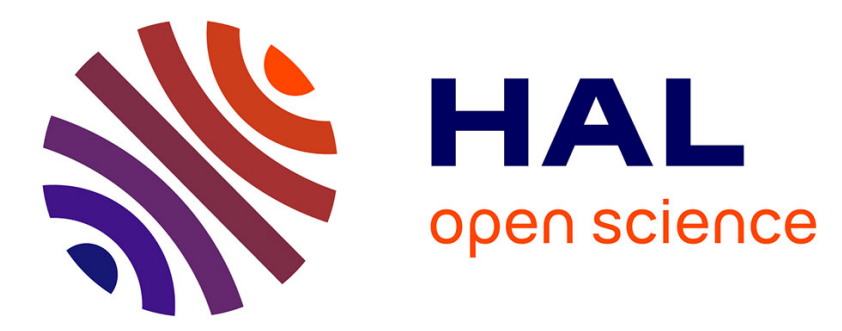

\title{
Nonlinear Control for DC Microgrids Enabling Efficient Renewable Power Integration and Ancillary Services for AC Grids
}

\author{
Alessio Iovine, Miguel Jimenez Carrizosa, G. Damm, Pedro Alou
}

\section{- To cite this version:}

Alessio Iovine, Miguel Jimenez Carrizosa, G. Damm, Pedro Alou. Nonlinear Control for DC Microgrids Enabling Efficient Renewable Power Integration and Ancillary Services for AC Grids. IEEE Transactions on Power Systems, 2019, 34 (6), pp.5136-5146. 10.1109/TPWRS.2018.2871369 . hal02936777v1

HAL Id: hal-02936777

https://hal-centralesupelec.archives-ouvertes.fr/hal-02936777v1

Submitted on 11 Sep 2020 (v1), last revised 4 Nov 2021 (v2)

HAL is a multi-disciplinary open access archive for the deposit and dissemination of scientific research documents, whether they are published or not. The documents may come from teaching and research institutions in France or abroad, or from public or private research centers.
L'archive ouverte pluridisciplinaire HAL, est destinée au dépôt et à la diffusion de documents scientifiques de niveau recherche, publiés ou non, émanant des établissements d'enseignement et de recherche français ou étrangers, des laboratoires publics ou privés. 


\section{Nonlinear Control for DC MicroGrids enabling Efficient Renewable Power Integration and Ancillary Services for AC grids}

\begin{tabular}{|r|l|}
\hline Journal: & IEEE Transactions on Power Systems \\
\hline Manuscript ID & TPWRS-00292-2018.R1 \\
\hline Manuscript Type: & $\begin{array}{l}\text { ONLY BY INVITATION-Special Section: Advanced Methods in Grid Operation } \\
\text { and Planning with High Penetration of Distributed Energy Resources }\end{array}$ \\
\hline Date Submitted by the Author: & n/a \\
\hline Complete List of Authors: & $\begin{array}{l}\text { Iovine, Alessio; Efficacity Institute } \\
\text { Jiménez Carrizosa, Miguel; Universidad Politecnica de Madrid Escuela } \\
\text { Tecnica Superior de Ingenieros Industriales, Centro Electrónica Industrial } \\
\text { DAMM, GILNEY; IBISC Laboratory, Evry Val d' Essonne University, France } \\
\text { Alou, Pedro; CEI-UPM }\end{array}$ \\
\hline Technical Topic Area : & Power system control, Power system reliability \\
\hline Key Words: & Nonlinear control, DC MicroGrids, Distributed systems \\
\hline \multicolumn{2}{|c}{}
\end{tabular}




\title{
Nonlinear Control for DC MicroGrids enabling Efficient Renewable Power Integration and Ancillary Services for AC grids
}

\author{
Alessio Iovine, Member, IEEE, Miguel Jiménez Carrizosa, Gilney Damm, Member, IEEE,
} Pedro Alou, Member, IEEE

\begin{abstract}
A nonlinear control able to perform voltage and power stability in Direct Current (DC) MicroGrids for an efficient renewable energy integration that is capable of providing frequency support to an Alternate Current (AC) grid is introduced in this work. A generic DC MicroGrid modeling is developed, and the introduced controllers are shown to ensure grid stability, both by a theoretical analysis with a formal proof of stability using Lyapunov techniques, than by simulations performed in MATLAB. A comparison with classical Proportional Integral (PI) control techniques is described to show the performance improvements.
\end{abstract}

Index terms- Nonlinear control, DC MicroGrids, Lyapunov control, Input-to-State Stability, Renewable energy, distributed systems, Plug\%Play.

\section{NOMENCLATURE}

$\begin{array}{ll}e & \text { error } \\ I_{P V} & \text { Current provided by solar panel } \\ P_{m} & \text { Mechanical power } \\ \omega & \text { AC grid pulsation } \\ s_{j} & \text { Duty cycle of converter } j \\ V_{B} & \text { Voltage in the battery } \\ V_{S} & \text { Voltage in the supercapacitors } \\ x_{i} & \text { state variable } \\ x_{i}^{*} & \text { Reference values } \\ z_{i} & \text { Internal reference trajectories } \\ \chi_{i} & \text { Extended state variable } \\ W & \text { Lyapunov function }\end{array}$

\section{INTRODUCTION}

$\mathbf{R}$ ENEWABLE Energy Sources (renewables) integration is a capital topic for future electrical grids. Their intermittent nature is a challenge from the control point of view, since it causes significant disturbances (voltage sags, frequency perturbations, etc...) into the transmission and distribution Alternate Current (AC) grids. [1].

A possibility for a better integration of renewable energies is the utilization of Direct Current (DC) MicroGrids including different storage devices in a distributed way [2], [3], [4], [5], [6], [7], [8], [9]. Indeed, the DC MicroGrids could be capable

A. Iovine is with Efficacity Research Center, Paris, France. Email: a.iovine@efficacity.com

M. Jiménez Carrizosa and P. Alou are with the Centro de Electrónica Industrial, Universidad Politécnica de Madrid, CEI-UPM, Spain. Email: miguel.jimenezcarrizosa@upm.es, pedro.alou@upm.es

G. Damm is with IBISC, Universit Paris Saclay, France. Email: gilney.damm@ibisc.fr of supplying to the main $\mathrm{AC}$ grid the produced renewable energy in a controllable way, and providing ancillary services to it. Ancillary services are defined as services that are procured by the AC grid operators with the objective of maintaining the stability of the power system [10], [11]. Traditionally, ancillary services have been provided by generators; however, the integration of renewable energies and the development of smart grids have prompted new opportunities to provide ancillary services like sub-second frequency support and synthetic inertia. These services generally include: frequency control, reactive power and voltage control, spinning reserves, system protection, loss compensation scheduling and dispatch [12]. Besides the capability to provide them, DC MicroGrids are also attracting interest thanks to different reasons: the fact that most renewable energies, storage and modern low voltage loads are DC (photovoltaic panels, batteries, computers or electric cars), the lack of reactive power or the increased capability of power converters in terms of performance and efficiency. Because of these reasons, a probable future framework for the electrical grid will be composed by the coexistence between $\mathrm{AC}$ and $\mathrm{DC}$ grids both for transmission and distribution levels. In this context, DC distributed MicroGrids would help to increase the $\mathrm{AC}$ grids resilience by provision of ancillary services. Proper operation conditions of an isolated DC distributed MicroGrid can be ensured by using different time scale storage devices (batteries, supercapacitors, fuel cells, etc..), in order to obtain a flexible and reliable system in response to the intermittent nature of renewable energies. The batteries could have the duty to provide energy when it is missing from the renewable sources, while other faster devices, as for example the supercapacitors, could act to compensate the power transient variations in power production or consumption. [13], [14]. Even slower elements like fuel cells or small scale pumped storage can allow long term stability and economic efficiency, but for slow term stability purposes they can be assimilated to a battery.

To correctly manage and control the power in the DC MicroGrids, the control task must be fulfilled in different time scales according to a hierarchical control [15], [16], [17] . Formal stability analysis of power systems in general, and MicroGrids in particular, is an open research topic, and several recent works are available in literature. Either cooperative control for enhance voltage harmonics and unbalances (see [18]) or robust control strategy for autonomous modes of operation of a microgrid that includes multiple distributed 
energy resource (DER) units are discussed [19]. Several works are based on linear controllers, or on nonlinear controllers for individual devices [20]: just recently, some stability analysis results regarding the interconnection of the power systems as a unique entity are available [21], [22], [13]].

In this paper, only the lower level real-time controller is presented; it is then shown to properly address voltage and current references which are given by a higher controller [15], [23], [24], [25], [26], in order to keep DC MicroGrid stability and support voltage and frequency of the main $\mathrm{AC}$ grid. The system modeling is developed and a complete stability analysis is investigated to meet power balance and voltage grid stability requirements, according to the framework introduced in [27]. To the purpose of being able to provide power to the $\mathrm{AC}$ grid, hypothesis on long-term power availability are done, as in [13], [28]. With respect to these works, a more complex modeling of the DC MicroGrids is considered, either for the DC and the AC sides. Indeed, the fast storage devices in charge of stabilizing the grid are connected by more economically desirable converter topologies as the bidirectional boost-buck converters, which unfortunately have nonminimum phase properties impacting their dynamical behaviour when performing the desired task. Furthermore, the Constant Power Load (CPL) possibility is considered to be handled as well [29], [30]. Moreover, the AC/DC converter dedicated to manage the interconnection of the two grids describes the frequency variations taking place in the $\mathrm{AC}$ side. Then, a more complex and general model is obtained for a DC MicroGrid composed by several subsystems. Such increased complexity results in the need for more complex control techniques, to the purpose to obtain a formal stability proof. All the converters in the introduced system must, in a distributed way, keep the stability of the mixed DC/AC network interconnecting all the subsystems. Nonlinear control techniques as backstepping, dynamic feedback linearization and Input-to-State Stability (ISS) are used to provide an ISS-like Lyapunov function for the whole system model (see [31], [32], [33]). The choice of ISS has been done to obtain simplified control laws.

With respect to the current literature, the main contribution of this work is to introduce a more general efficient distributed control action among several devices connected to a DC MicroGrid for providing frequency support to an AC grid regulating both active and reactive power, while keeping the DC one under stable operation conditions. The stability of the proposed control action is ensured by an ISS-like Lyapunov function, ensuring proper interconnection of the several subsystems as a unique power systems entity [27], [34], [33]. To the purpose of showing the effectiveness of the proposed control action, voltage and frequency variations are considered in the AC side, and the DC MicroGrid is responsible to keep the AC grid operating in its nominal operation point. Since CPL is one of the the major source of instabilities in distributed grids [35], the control strategy will be shown capable to deal with such situation in the DC side. The final management system can be configurable and adaptable as needed.

This paper is outlined as follows: in Section $\Pi$ the system model is introduced, while Section III depicts the adopted nonlinear control and the stability analysis. Section IV shows simulation results, and a comparison with classical PI controllers. Finally, Section $\mathrm{V}$ provides conclusions and related future works.

\section{MicroGrid Modeling}

Figure 1 depicts a possible configuration of the future electric network, where both AC and DC system will exist together with a high renewable energy penetration and where the storage devices will be key elements for the system stabilization.

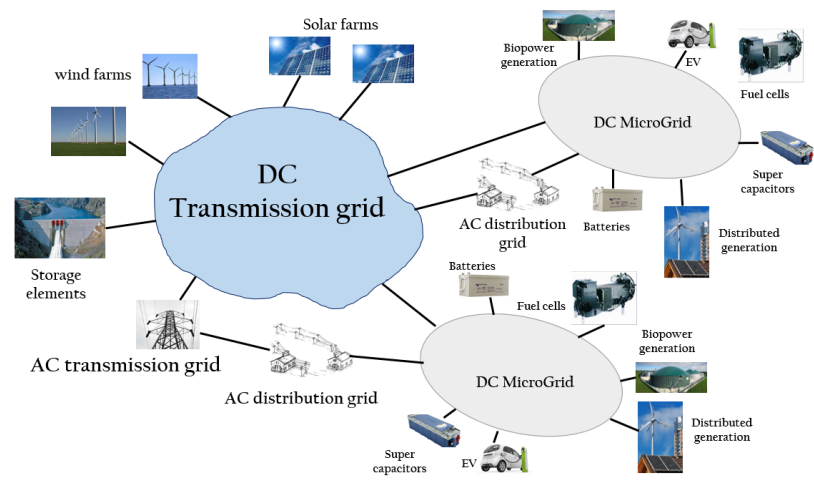

Fig. 1. The future electric network.

This paper is focused on the control of a DC MicroGrid enabling the possibility to provide ancillary services (frequency support) to an AC grid. As shown in Figure 1, the DC MicroGrid can be composed by different types of distributed renewable energies as photovoltaics (PV) or wind farms, batteries, super capacitors, fuel cells, Biopower generation, AC loads, DC loads, Electric Vehicles (EV) chargers connections to different DC or AC grids, etc... Distinctive elements are both the type of converters and their applications: to take into account such distinctions, a classification is provided in the following.

\section{A. DC/DC converters for renewable energy integration}

This type of converter is mainly used for PV applications. Clearly, the energy in the converter always goes in the same direction, and consequently both Buck or Boost configurations could be used, depending on the relation between input and output voltages. In order to obtain the model, average technique is utilized, which is a well established technique [36]. Besides, ideal switches have been considered.

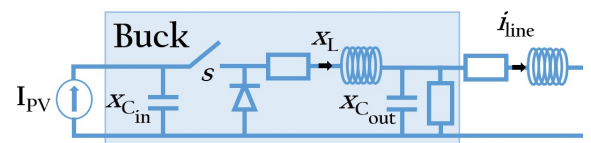

a)

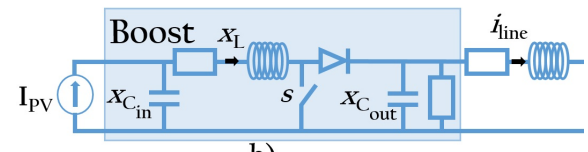

b)

Fig. 2. a) Buck converter

b) Boost converter 
The average model of the electrical schemes in Figure 2 is introduced by the set of equations (1) and (2) for Buck and Boost converters, respectively:

$$
\begin{aligned}
& \dot{x}_{C_{\text {in }}}=\frac{I_{P V}}{C_{\text {in }}}-\frac{s}{C_{i n}} x_{L} \\
& \dot{x}_{L}=-\frac{R}{L} x_{L}+\frac{s}{L} x_{C_{\text {in }}}-\frac{1}{L} x_{C_{\text {out }}} \\
& \dot{x}_{C_{\text {out }}}=-\frac{g}{C_{\text {out }}} x_{C_{\text {out }}}+\frac{1}{C_{\text {out }}} x_{L}-\frac{1}{C_{\text {out }}} i_{\text {line }} \\
& \dot{x}_{C_{\text {in }}}=\frac{I_{P V}}{C_{\text {in }}}-\frac{1}{C_{i n}} x_{L} \\
& \dot{x}_{L}=-\frac{R}{L} x_{L}+\frac{1}{L} x_{C_{\text {in }}}-\frac{s}{L} x_{C_{\text {out }}} \\
& \dot{x}_{C_{\text {out }}}=-\frac{g}{C_{\text {out }}} x_{C_{\text {out }}}+\frac{s}{C_{\text {out }}} x_{L}-\frac{1}{C_{\text {out }}} i_{\text {line }}
\end{aligned}
$$

with

$$
I_{P V}=I_{p v}-I_{0}\left(e^{\frac{q V}{k T}}-1\right)-\frac{V+I R_{s}}{R_{s}}
$$

where $I_{P V}$ is the current provided by the solar panel, and $i_{\text {line }}$ is the current thought the line which links the converters and the DC MicroGrid. Here $I$ is the solar cell current, $I_{p v}$ is the irradiance generated current, $I_{0}$ is the diode saturation current, $q$ is the electron charge, $K$ is the Boltzman constant, $T$ is the cell temperature in Kelvin, $V$ is the solar cell output voltage and $R_{s}$ is the solar cell series resistance.

\section{B. $D C / D C$ bidirectional converter}

This type of converter is used when the power can flow in both directions. Usually, it appears in storage devices or in nodes which connects different DC grids. Although there exist several topologies for this task, in this paper the Buck-Boost bidirectional converter has been chosen due to its simplicity. Its average model is introduced by the following set of equations:

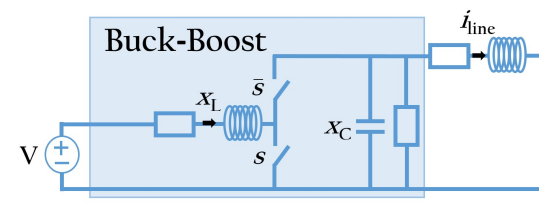

Fig. 3. DC-DC bidirectional converter

$$
\begin{aligned}
& \dot{x}_{L}=-\frac{R}{L} x_{L}-\frac{s}{L}+\frac{V}{L} \\
& \dot{x}_{C}=-\frac{g}{C} x_{C}+\frac{s}{C} x_{L}-\frac{1}{C} i_{\text {line }}
\end{aligned}
$$

\section{DC/DC converter for DC loads}

Due to the fact that only one power direction is needed for this type of application, the type of converters is similar to the one introduced in Section III-A

\section{AC/DC converter}

AC/DC converters are nowadays used in several applications, such as interconnecting $\mathrm{AC}$ and $\mathrm{DC}$ grids, integrating wind energy in the DC grid or supplying power to a AC load. In this work a three phases Voltage Source Converter (VSC) converter is analyzed (see Figure 4). In addition, as the main goal of the paper is to provided frequency support, $\omega$ has been also taken into account in the modeling. Besides, the $d q 0$ frame has been used to model the system, which results in the following equations:

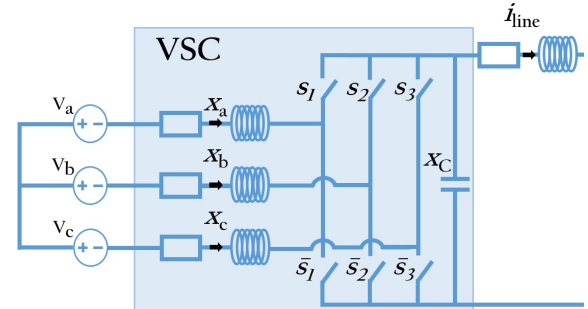

Fig. 4. Voltage Source Converter

$$
\begin{aligned}
& \dot{x}_{d}=-\frac{R}{L} x_{d}-\omega x_{q}-u_{d} x_{C}+v_{d} \\
& \dot{x}_{q}=-\frac{R}{L} x_{q}+\omega x_{d}-u_{q} x_{C}+v_{q} \\
& \dot{x}_{0}=-\frac{R}{L} x_{0}+v_{0} \\
& \dot{x}_{C}=-\frac{3}{2 C x_{C}}\left(v_{d} x_{d}+v_{q} x_{q}+v_{0} x_{0}\right)+\frac{1}{C} i_{\text {line }} \\
& \dot{\omega}=\alpha\left[P_{m}-\frac{3}{2}\left(v_{d} x_{d}+v_{q} x_{q}+v_{0} x_{0}\right)\right]
\end{aligned}
$$

where the term $\alpha$ depends on the inertia of all the AC generators and $P_{m}$ is the total mechanic power supplied by the prime mover. As a frequency variation in the system implies a voltage variation in the $\mathrm{AC}$ sources $\left(v_{d}, v_{q}\right.$ and $\left.v_{0}\right)$, the following conditions describing such voltage variations have been also considered [37]:

$$
\begin{aligned}
& v_{d}=r x_{d}-l \omega x_{q} \\
& v_{q}=r x_{q}+l \omega x_{d} \\
& v_{0}=\left(r+3 r_{n}\right) x_{0}
\end{aligned}
$$

Here $r, r_{n}$ and $l$ are the resistance, neutral resistance and inductance of the equivalent generator of the $\mathrm{AC}$ side.

\section{E. DC MicroGrid Modeling}

To the purpose to identify a single model for the whole DC MicroGrid, here the model introduced in Sections II-A, II-B III-C and II-D are used to obtain the model of a generic DC MicroGrid integrating renewables (a PV array), storages acting at different time scales (a battery and a supercap), a DC load operating either as Constant Impedance Load (CIL) or CPL and, finally, the connection to an AC grid (see Figure 5). It is composed of 5 nodes, 4 DC lines and 5 converters. Intermittent energy resource is represented by solar panels, where Maximum Power Point Tracking (MPPT) control is applied. Both batteries and supercapacitors are implemented in order to have different dynamics. Besides, a new nonlinear approach for CPL based on backstepping technique is addressed [38] . To control purposes, the MicroGrid model is defined as

$$
\dot{x}(t)=f(x(t))+g(x(t)) u(t)+h(d(t))
$$

The whole dynamical model is considering the equations introduced in (2), (4), (5) and (6), and is introduced in the system in (11) and (12). The state and the disturbances are supposed to be measurable. The state $x \in \mathbb{R}^{17}$ is composed by currents, voltages and the pulsation as follows: $x_{1}$ is the input capacitor $\left(C_{1}\right)$ in the $\mathrm{PV}$ converter; $x_{2}, x_{5}, x_{8}$ are the inductor $\left(L_{2}, L_{5}, L_{8}\right)$ currents and $x_{3}, x_{6}, x_{9}$ are the output capacitors $\left(C_{3}, C_{6}, C_{9}\right)$ voltages of the PV, battery and supercapacitor converter, respectively; $x_{4}, x_{7}, x_{10}, x_{11}$ are the inductor $\left(L_{4}, L_{7}, L_{10}, L_{11}\right)$ currents in the line 1-5, $2-5,3-5,4-5$, respectively; $x_{12}$ is the capacitor $C_{12}$ voltage 
in the converter connected to the DC load, while $x_{13}$ is the capacitor $C_{13}$ voltage in the AC/DC converter; $x_{14}, x_{15}, x_{16}$, are the $d, q, 0$ axes of the AC current, respectively, while $x_{17}$ is the pulsation $\omega$ of the $\mathrm{AC}$ grid.

The control input $u \in \mathbb{R}^{6}$ is composed by the different duty cycles of the devices: PV, battery, supercapacitor, DC load and $\mathrm{AC}$ connected converter, respectively, see (8). The disturbance vector $d \in \mathbb{R}^{5}$ is introduced in 10 , and it is supposed to be piecewise constant. Here $I_{P V}\left(x_{1}\right)$ is the current in 3 ,,$V_{B}$ and $V_{S}$ are the voltages of battery and supercapacitor, $R_{L}$ the load resistance for the CIL case, or $P_{L}$ for the CPL case. The meaning of the parameters can be easily understood by the aforementioned modeling.

$$
\begin{aligned}
& u=\left[\begin{array}{llllll}
s_{1} & s_{2} & s_{4} & s_{6} & u_{d} & u_{q}
\end{array}\right] \\
& d^{C I L}=\left[\begin{array}{llllll}
I_{P V}\left(x_{1}\right) & V_{B} & V_{S} & R_{L} & P_{m}
\end{array}\right] \\
& d^{C P L}=\left[\begin{array}{llllll}
I_{P V}\left(x_{1}\right) & V_{B} & V_{S} & P_{L} & P_{m}
\end{array}\right]
\end{aligned}
$$

$$
\left\{\begin{array}{l}
\dot{x}_{1}=\frac{1}{C_{1}} I_{P V}\left(x_{1}\right)-\frac{1}{C_{1}} x_{2} \\
\dot{x}_{2}=-\frac{R_{2}}{L_{2}} x_{2}+\frac{1}{L_{2}} x_{1}-\frac{1}{L_{2}} s_{1} x_{3} \\
\dot{x}_{3}=-\frac{g_{3}}{C_{3}} x_{3}-\frac{1}{C_{3}} x_{4}+\frac{1}{C_{3}} s_{1} x_{2} \\
\dot{x}_{5}=-\frac{R_{4}}{L_{4}} x_{4}+\frac{1}{L_{4}} x_{3}-\frac{1}{L_{4}} x_{13} \\
\dot{x}_{6}=-\frac{R_{5}}{L_{5}} x_{5}-\frac{1}{L_{5}} x_{6} s_{2} x_{6}+\frac{1}{C_{5}} V_{B} \\
\dot{x}_{7}=-\frac{1}{L_{7}} x_{7} x_{7}+\frac{1}{C_{6}} s_{2} x_{5} \\
\dot{x}_{8}=-\frac{R_{8}}{L_{8}} x_{8}+\frac{1}{L_{8}} V_{s}-\frac{1}{L_{8}} s_{4} x_{9} \\
\dot{x}_{9}=-\frac{g_{9}}{C_{9}} x_{9}-\frac{1}{C_{9}} x_{10}+\frac{1}{C_{9}} s_{4} x_{8} \\
\dot{x}_{10}=-\frac{R_{10}}{L_{10}} x_{10}+\frac{1}{L_{10}} x_{9}-\frac{1}{L_{10}} x_{13} \\
\dot{x}_{11}=-\frac{R_{11}}{L_{11}} x_{11}-\frac{1}{L_{11}} s_{6} x_{12}+\frac{1}{L_{11}} x_{13} \\
\dot{x}_{12}=F\left(d, x_{12}\right)+\frac{1}{C_{12}} s_{6} x_{11} \\
\dot{x}_{13}=\frac{3}{2} \frac{1}{C_{13}} \frac{1}{x_{13}}\left[v_{d} x_{14}+v_{q} x_{15}+v_{0} x_{16}\right]+ \\
\quad+\frac{1}{C_{13}}\left[x_{4}+x_{7}+x_{10}-x_{11}\right] \\
\dot{x}_{14}=\frac{1}{L_{14}}\left[-R_{A C} x_{14}-L_{14} x_{17} x_{15}-u_{d} x_{13}+v_{d}\right] \\
\dot{x}_{15}=\frac{1}{L_{15}}\left[-R_{A C} x_{15}+L_{15} x_{17} x_{14}-u_{q} x_{13}+v_{q}\right] \\
\dot{x}_{16}=\frac{1}{L_{16}}\left[-R_{A C} x_{16}+v_{0}\right] \\
\dot{x}_{17}=\alpha\left[P_{m}-\frac{3}{2}\left(v_{d} x_{14}+v_{q} x_{15}+v_{0} x_{16}\right)\right]
\end{array}\right.
$$

where $F\left(d, x_{12}=-\frac{1}{R_{L}} \frac{1}{C_{12}} x_{12}\right.$ if a CIL is considered, and $F\left(d, x_{12}=-\frac{P_{L}}{x_{12}}\right.$ in case of a CPL.

$$
\begin{aligned}
& v_{d}=r x_{14}-l x_{17} x_{15} ; \quad v_{q}=l x_{17} x_{14}+r x_{15} \\
& v_{0}=\left(r+3 r_{n}\right) x_{16}
\end{aligned}
$$

The main target of this work is to impose a desired pulsation value $x_{17}^{*}$ to the $\mathrm{AC}$ grid, while keeping the $\mathrm{DC}$ grid and the load at some desired voltage levels, which are $x_{12}^{*}$ and $x_{13}^{*}$, respectively. When considering the problem of having
CPL, the current reference $x_{11}^{*}$ will be used instead of the voltage reference $x_{12}^{*}$. It is then necessary to consider the hypothesis to have good references for the other physical devices, which are given by a higher controller. It provides current or voltage references for each converter depending on the node nature. In addition, this controller could be optimal in order to minimize the losses of the system or to optimize the utilization cost of the storage devices, but always guaranteeing the energy balance and keeping each element of the system within its appropriate parameters, in order to ensure global stability at any instant [23], [24], [25]. Consequently, a higher level controller is supposed to provide the voltage references $x_{3}^{*}$ (coming from a MPPT algorithm) for the PV array and $x_{5}^{*}$ (coming from a battery management system BMS as [26]), for the battery current.

\section{MicroGrid CONTROL}

As already mentioned in Section [II-E target of this paper is to provide an analytical result where each DC/DC converter develops a proper control action to the purpose to fit some desired targets, as the tracking of MPPT, battery, pulsation, load and grid references, which are $x_{3}^{*}, x_{5}^{*}, x_{17}^{*}, x_{11}^{*}$ or $x_{12}^{*}$, $x_{13}^{*}$, respectively, to the purpose to ensure grid stability. The grid control is based on a ISS-like Lyapunov function [33], which is used to develop the control laws and consequently to ensure stability results. Main objectives are to provide frequency support in the $\mathrm{AC}$ side, as well as keeping the DC voltage grid at desired values and guaranteeing the DC loads service. The supercapacitor will be in charge of keeping voltage stability during transients in the DC grid, while the other devices will operate power balance in long term [13], [14]. The DC grid bus is $x_{13}$ : it is influenced by the connection with load and sources. To counteract to the variations taking place, the control task is split in several purposes. Some considerations about the considered value of $R_{L}$ and $P_{m}$ must be done , similarly as in [13], and on the existence and dimension of a proper operating region. Indeed, such values must be in a set $\Omega_{R P}$ such that $\Omega_{*}$, i.e. the set of all possible values of $x_{3}^{*}, x_{5}^{*}, x_{11}^{*}$ or $x_{12}^{*}, x_{13}^{*}$ and $x_{17}^{*}$, is not empty with respect to the values of $V_{B}, V_{S}$, and the physical limitations of the system and of the control inputs, which are

$$
\begin{aligned}
s_{j} & \in[0,1], j=\{1,2,4,6\} \\
u_{d}, u_{q} & \in[-1,1], \sqrt{u_{d}^{2}+u_{q}^{2}}=1
\end{aligned}
$$

With respect to the considered reference values $x_{3}^{*}, x_{5}^{*}, x_{12}^{*}$, $x_{13}^{*}$ and $x_{17}^{*}$, and choosing to have a fixed reference $x_{15}^{*}$ for $x_{15}$ as well, let us define the reference trajectories $z_{2}, z_{8}, z_{9}$, $z_{10}, z_{11}, z_{14}$ for the dynamics $x_{2}, x_{8}, x_{9}, x_{10}, x_{11}, x_{14}$ as

$$
\begin{gathered}
z_{2}=\int \frac{x_{3}}{x_{1}-2 R_{2} z_{2}}\left[\frac{1}{x_{3}} \dot{x}_{1}-z_{2}\left(\frac{1}{x_{3}^{2}}\left(x_{1}-R_{2} z_{2}\right)\right)\right]+ \\
-\int \frac{C_{3} x_{3}}{x_{1}-2 R_{2} z_{2}}\left[\frac{1}{C_{3}} \dot{x}_{4}+\frac{g_{3}}{C_{3}} \dot{x}_{3}-\bar{K}_{3}\left(x_{3}-x_{3}^{*}\right)-\underline{K}_{3} \dot{x}_{3}\right] \\
z_{8}=\int \frac{x_{9}}{V_{S}-2 R_{8} z_{8}}\left[g_{9} \dot{x}_{9}+\dot{z}_{10}+\frac{1}{x_{9}^{2}} z_{8}\left(V_{S}-R_{8} z_{8}\right)\right]+ \\
\quad-\int \frac{C_{9} x_{9}}{V_{S}-2 R_{8} z_{8}}\left[\bar{K}_{9}\left(x_{9}-z_{9}\right)+\underline{K}_{9}\left(\dot{x}_{9}-\dot{z}_{9}\right)\right] \\
z_{9}=R_{10} x_{10}-\alpha_{10}+x_{13}+L_{10} \dot{z}_{10}-K_{10}\left(x_{10}-z_{10}\right)
\end{gathered}
$$




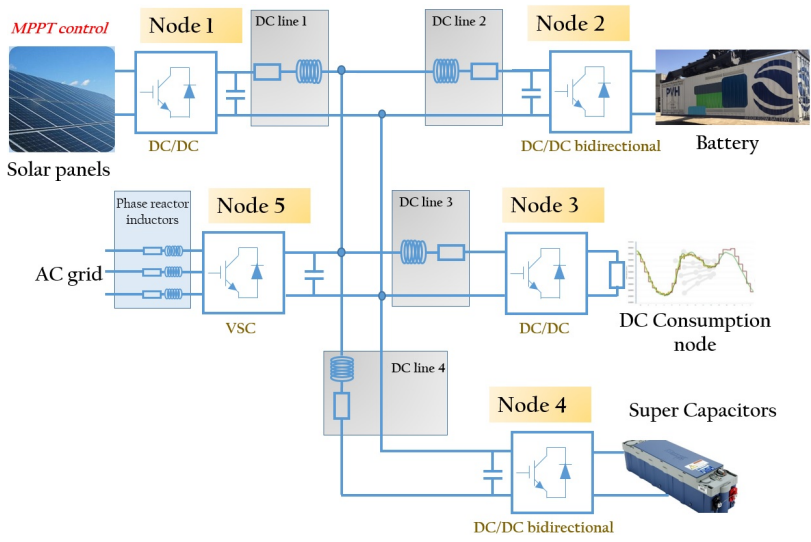

Fig. 5. The considered DC MicroGrid providing ancillary services to the AC network.

$$
\begin{gathered}
z_{10}=\left[-\frac{3}{2} \frac{1}{x_{13}}\left(v_{d} x_{14}+v_{q} x_{15}+v_{0} x_{16}\right)\right]+ \\
\left.+\left[-x_{4}-x_{7}+x_{11}-K_{13} x_{13}+K_{13} \frac{1}{x_{13}} x_{13}^{*}{ }^{2}\right)\right] \\
z_{11}^{C I L}=\int \frac{x_{12}}{x_{13}-2 R_{11} z_{11}}\left[\frac{1}{R_{L}} \dot{x}_{12}+\frac{1}{x_{12}^{2}}\left(x_{13}-R_{11} z_{11}\right) z_{11}\right]- \\
-\int \frac{C_{12} x_{12}}{x_{13}-2 R_{11} z_{11}}\left[\frac{1}{C_{12}} \frac{1}{x_{12}} z_{11} \dot{x}_{13}+\bar{K}_{12}\left(x_{12}-x_{12}^{*}\right)+\underline{K}_{12}\left(\dot{x}_{12}\right)\right] \\
z_{11}^{C P L}=\int \frac{x_{12}}{x_{13}-2 R_{11} z_{11}}\left[\frac{1}{x_{12}^{2}} P \dot{x}_{12}+\frac{1}{x_{12}^{2}}\left(x_{13}-R_{11} z_{11}\right) z_{11}\right]- \\
-\int \frac{C_{12} x_{12}}{x_{13}-2 R_{11} z_{11}}\left[\frac{1}{C_{12}} \frac{1}{x_{12}} z_{11} \dot{x}_{13}+\bar{K}_{12}\left(x_{12}-x_{12}^{*}\right)+\underline{K}_{12}\left(\dot{x}_{12}\right)\right] \\
z_{14}=\frac{1}{v_{d}}\left[\frac{2}{3}\left(P_{m}+\alpha_{17}+K_{17}\left(x_{17}-x_{17}^{*}\right)\right)-v_{q} x_{15}-v_{0} x_{16}\right]
\end{gathered}
$$

where the terms $\alpha_{10}$ and $\alpha_{17}$ are integral error terms ensuring zero error in steady-state, i.e.

$$
\dot{\alpha}_{10}=K_{10}^{\alpha}\left[x_{10}-z_{10}\right] ; \quad \dot{\alpha}_{17}=K_{17}^{\alpha}\left[x_{17}-x_{17}^{*}\right]
$$

and the equilibrium points of the remaining dynamics of the system (11) in closed loop are

$$
\begin{aligned}
& x_{1}^{e}=f\left(I\left(x_{3}^{e}\right)\right) ; \quad x_{4}^{e}=\frac{x_{3}^{*}-x_{13}^{*}}{R_{4}} ; \\
& x_{6}^{e}=\frac{s_{2}^{e} x_{5}^{*}-x_{7}^{e}}{g_{6}} ; \quad x_{7}^{e}=\frac{x_{6}^{e}-x_{13}^{*}}{R_{7}} ; x_{16}^{e}=0
\end{aligned}
$$

where $s_{2}^{e}$ is the value of $s_{2}$ at the equilibrium. Such reference trajectories are defined to the purpose to force the equilibrium point of the selected dynamics to be the desired one. The $K_{i}$ are defined as positive tuning parameters, calculated according to some conditions (see [13]): in the following of the paper, any gain $K_{i}, \bar{K}_{i}$ and $\underline{K}_{i}$ are defined in the same way. According to considering CPL or CIL case, the trajectory $z_{11}^{i}$ is used accordingly, $i \in C P L, C I L$. Thus, in order to force the system to have both the desired equilibrium and trajectories, the following control laws are introduced:

$$
\begin{aligned}
& s_{1}=\frac{1}{x_{3}}\left[x_{1}-R_{2} x_{2}+\alpha_{2}-L_{2} \dot{z}_{2}+K_{2}\left(x_{2}-z_{2}\right)\right](25) \\
& s_{2}=\frac{1}{x_{6}}\left[V_{B}+\alpha_{5}-R_{5} x_{5}+K_{5}\left(x_{5}-x_{5}^{*}\right)\right] \\
& s_{4}=\frac{1}{x_{9}}\left[\alpha_{8}-R_{8} x_{8}+V_{S}-L_{8} \dot{z}_{8}+K_{88}\left(x_{8}-z_{8}\right)\right]
\end{aligned}
$$

$$
\begin{gathered}
s_{6}=\frac{1}{x_{12}}\left[\alpha_{11}-R_{11} x_{11}+x_{13}-L_{11} \dot{z}_{11}+K_{11}\left(x_{11}-z_{11}\right)\right] \\
u_{d}=\frac{1}{x_{13}}\left[v_{d}-R_{A C} x_{14}-L_{14} x_{17} x_{15}+\alpha_{14}\right]+ \\
\quad+\frac{1}{x_{13}}\left[-L_{14} \dot{z}_{14}+K_{14}\left(x_{14}-z_{14}\right)\right] \\
u_{q}=\frac{1}{x_{13}}\left[v_{q}-R_{A C} x_{15}+L_{15} x_{17} x_{14}\right]+ \\
\quad+\frac{1}{x_{13}}\left[\alpha_{15}+K_{15}\left(x_{15}-x_{15}^{*}\right)\right]
\end{gathered}
$$

with the integral error terms ensuring zero error in steady-state;

$$
\begin{aligned}
\dot{\alpha}_{2}=K_{2}^{\alpha}\left[x_{2}-z_{2}\right] ; \quad \dot{\alpha}_{5}=K_{5}^{\alpha}\left[x_{5}-x_{5}^{*}\right] \\
\dot{\alpha}_{8}=K_{8}^{\alpha}\left[x_{8}-z_{8}\right] ; \quad \dot{\alpha}_{11}=K_{11}^{\alpha}\left[x_{11}-z_{11}\right] \\
\dot{\alpha}_{14}=K_{14}^{\alpha}\left[x_{14}-z_{14}\right] ; \quad \dot{\alpha}_{15}=K_{15}^{\alpha}\left[x_{15}-x_{15}^{*}\right]
\end{aligned}
$$

To the purpose to study stability of the system in (11), and thanks to the introduction of the aforementioned dynamics, it is now possible to define the extended state $\chi$ and its equilibrium point $\chi^{e}$ :

$$
\chi=\left[\begin{array}{lllll}
\chi_{1} & \chi_{2} & \chi_{3} & \chi_{4} & \chi_{5}
\end{array}\right] ; \quad \chi^{e}=\left[\begin{array}{lllll}
\chi_{1}^{e} & \chi_{2}^{e} & \chi_{3}^{e} & \chi_{4}^{e} & \chi_{5}^{e}
\end{array}\right]
$$

where

$$
\begin{aligned}
& \chi_{1}=\left[\begin{array}{llll}
x_{1} & x_{2} & \alpha_{2} & x_{3} x_{4}
\end{array}\right]^{T} ; \quad \chi_{1}^{e}=\left[\begin{array}{lllll}
x_{1}^{e} & z_{2} & 0 & x_{3}^{*} & x_{4}^{e}
\end{array}\right]^{T} \text { (35) } \\
& \chi_{2}=\left[\begin{array}{llll}
x_{5} & \alpha_{5} & x_{6} & x_{7}
\end{array}\right]^{T} ; \quad \chi_{2}^{e}=\left[\begin{array}{llll}
x_{5}^{*} & 0 & x_{6}^{e} & x_{7}^{e}
\end{array}\right]^{T} \\
& \chi_{3}=\left[\begin{array}{llll}
x_{8} & \alpha_{8} & x_{9} \dot{x}_{9} x_{10} \alpha_{10}
\end{array}\right]^{T}
\end{aligned}
$$

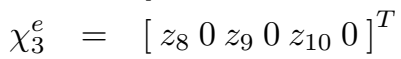

$$
\begin{aligned}
& \chi_{4}=\left[\begin{array}{llll}
x_{11} & \alpha_{11} & x_{12} & \dot{x}_{12}
\end{array}\right]^{T} ; \quad \chi_{4}^{e}=\left[\begin{array}{llll}
z_{11} & 0 & x_{12}^{*} & 0
\end{array}\right]^{T}(39) \\
& \chi_{5}=\left[\begin{array}{lllll}
x_{13} & \alpha_{13} x_{14} \alpha_{14} x_{15} \alpha_{15} x_{16} x_{17} \alpha_{17}
\end{array}\right]^{T}
\end{aligned}
$$

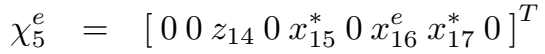

with $\dot{x}_{j}, j \in\{9,12\}$ being the time derivatives of $x_{j}$. The extended states are composed by the state variables and the needed control dynamics (as integral terms or other time derivative used in the control laws) for each devices composing the DC MicroGrid: $\chi_{4}$ refers to the subsystems controlling the supercapacitor power output, having as target the DC voltage control, while $\chi_{1}, \chi_{2}, \chi_{3}$ and $\chi_{5}$ describes the PV, battery, load and connection to the AC grid subsystems, respectively, having as target the power output tracking of the references provided by the higher level controller.

Finally, let us consider the error term $e$, where

$$
\begin{gathered}
e=\left[\chi_{1}-\chi_{1}^{e} ; \chi_{2}-\chi_{2}^{e} ; \chi_{3}-\chi_{3}^{e} ; \chi_{4}-\chi_{4}^{e} ; \chi_{5}-\chi_{5}^{e}\right] \\
=\left[e_{1} ; e_{2} ; e_{3} ; e_{4} ; e_{5}\right]
\end{gathered}
$$

and any evolution of $e$ such that

$$
\begin{aligned}
x_{3} & \neq 0, x_{6} \neq 0, x_{9} \neq 0, x_{12} \neq 0, x_{13} \neq 0, v_{d} \neq 0(43) \\
x_{1}-2 R_{2} z_{2} & \neq 0, V_{S}-2 R_{8} z_{8} \neq 0, x_{13}-2 R_{11} z_{11} \neq 0
\end{aligned}
$$

Theorem 1: For any given $x_{3}^{*}, x_{5}^{*}, x_{11}^{*}$ or $x_{12}^{*}, x_{13}^{*}, x_{17}^{*}$ in $\Omega_{*}$, and $R_{L}$ and $P_{m}$ in $\Omega_{R P}$ such that condition (43) is satisfied, the control inputs in (25), (26), (27), (28), (29), (30), are such that the system $e$ is ISS stable in closed loop, since there exists $\beta \in K \mathcal{L}$ and $\gamma \in K$ such that the following inequality holds

$$
|e(t)| \leq \beta(e(0), t)+\gamma\left(x_{13}^{*}\right),
$$


Proof 1: The proof is based on a stability analysis with respect to a Lyapunov function $W$ as a composition of Lyapunov functions [13], [27]:

$$
W=W_{e_{1}}+W_{e_{2}}+W_{e_{3}}+W_{e_{4}}+W_{e_{5}}>0
$$

where

$$
\begin{aligned}
& W_{e_{1}}=W_{1}+W_{2}+W_{3}+W_{4}>0 \\
& W_{e_{2}}=W_{5}+W_{6}+W_{7}>0 \\
& W_{e_{3}}=W_{8}+W_{9}+W_{10}>0 \\
& W_{e_{4}}=W_{11}+W_{12}>0 \\
& W_{e_{5}}=W_{13}+W_{14}+W_{15}+W_{16}+W_{17}>0
\end{aligned}
$$

A combination of nonlinear control techniques as backstepping, dynamic feedback linearization and Lyapunov analysis is used in this proof. It is composed of five parts: each of them show the stability of a converter connected to a device.

Let us start analyzing $W_{e_{5}}$. To prove the convergence of the frequency to the desired term, let us introduce $W_{17}$ as

$$
W_{17}=\frac{1}{2}\left(x_{17}-x_{17}^{*}\right)^{2}+\frac{1}{2 K_{17}^{\alpha}} \alpha_{17}^{2}>0
$$

The choice of the reference trajectory $z_{14}$ in 21) for $x_{14}$ demonstrates converge of $x_{17}$ to $x_{17}^{*}$, since

$$
\dot{W}_{17}=-K_{17}\left(x_{17}-x_{17}^{*}\right)^{2} \leq 0
$$

and by Barbalat's lemma utilization asymptotic convergence is ensured [31]. To show convergence of the currents of the AC grid to their references, the following functions are defined:

$$
\begin{aligned}
& W_{14}=\frac{L_{14}}{2}\left(x_{14}-z_{14}\right)^{2}+\frac{1}{2 K_{14}^{\alpha}} \alpha_{14}^{2}>0 \\
& W_{15}=\frac{L_{15}}{2}\left(x_{15}-x_{15}^{*}\right)^{2}+\frac{1}{2 K_{15}^{\alpha}} \alpha_{15}^{2}>0 \\
& W_{16}=\frac{1}{2}\left(x_{16}-x_{16}^{e}\right)^{2}>0
\end{aligned}
$$

The choice of the control inputs in 29 ) and (30) is such that

$$
\begin{aligned}
& \dot{W}_{14}=-K_{14}\left(x_{14}-z_{14}\right)^{2} \leq 0 \\
& \dot{W}_{15}=-K_{15}\left(x_{15}-x_{15}^{*}\right)^{2} \leq 0
\end{aligned}
$$

and asymptotic convergence can be ensured again by Barbalat's lemma. Furthermore,

$$
\dot{W}_{16}=-\frac{1}{L_{16}}\left(x_{16}-x_{16}^{e}\right)^{2}<0
$$

Then, to complete the stability analysis on $W_{e_{5}}$ let us consider the reference trajectory $z_{10}$ in 18 and the function

$$
W_{13}=\frac{1}{2}\left(x_{13}\right)^{2}>0
$$

After simple calculations, it is possible to show that $\dot{W}_{13}$ satisfies ISS conditions, since there exist functions $\bar{\beta}, \bar{\gamma} \in K_{\infty}$ such that

$$
\begin{array}{r}
\dot{W}_{13}\left(x_{13}, x_{13}^{*}\right)=-K_{13}\left(x_{13}\right)^{2}+K_{13}\left(x_{13}^{*}\right)^{2} \\
=-\bar{\beta}\left(\left|x_{13}\right|\right)+\bar{\gamma}\left(\left|x_{13}^{*}\right|\right)
\end{array}
$$

Then, to conclude this first step, we can state that $W_{e_{5}}>0$ admits a $\dot{W}_{e_{5}}$ ensuring ISS properties, since

$$
\dot{W}_{e_{5}}\left(e_{5}, x_{13}^{*}\right)=-\bar{\beta}\left(\left|e_{5}\right|\right)+\bar{\gamma}\left(\left|x_{13}^{*}\right|\right)
$$

The second step of this proof is dedicated to the part of system that has in charge of ensuring convergence of $x_{10}$ to its the reference trajectory in (18) (the supercapacitor), i.e. $W_{e_{4}}$. To this purpose, let us define $W_{10}$ as

$$
W_{10}=\frac{L_{10}}{2}\left(x_{10}-z_{10}\right)^{2}+\frac{1}{2 K_{10}^{\alpha}} \alpha_{10}^{2}>0
$$

The choice of the reference $z_{9}$ in (17) is clearly done to obtain a time derivative of $W_{10}$ that is negative semidefinite, where again Barbalat's lemma can be used to show asymptotic converge. Indeed, $\dot{W}_{10}$ results to be

$$
\dot{W}_{10}=-K_{10}\left(x_{10}-z_{10}\right)^{2} \leq 0
$$

Unfortunately, this backstepping-like procedure utilized until now cannot be directly used to obtain the reference $z_{8}$ that would impose the converge of $x_{9}$ to $z_{9}$ in (17). The reference in (16) has been then selected according to separation principle properties, which allow to consider the slow dynamics of $x_{9}$ when the fast dynamics $x_{8}$ is already in its reference trajectory, i.e. $x=8=z_{8}$ :

$$
\dot{x}_{9}=-\frac{g_{9}}{C_{9}} x_{9}-\frac{1}{C_{9}} x_{10}+\frac{1}{C_{9}} s_{4} z_{8}
$$

To the purpose to calculate $z_{8}$, the virtual input $\dot{z}_{8}=v_{d}$ is added to the system. To calculated it, a time derivative of equation (64) is needed. Then, it is easy to see that the choice of the reference in (16) has been done to have the resulting subsystem

$$
\left(\begin{array}{c}
\dot{x}_{9} \\
\ddot{x}_{9}
\end{array}\right)=\left(\begin{array}{cc}
0 & 1 \\
-\bar{K}_{8} & -\underline{K}_{8}
\end{array}\right)\left(\begin{array}{c}
x_{9} \\
\dot{x}_{9}
\end{array}\right)
$$

which is a linear and stable system for $\bar{K}_{8}, \underline{K}_{8}>0$. Consequently, there will exist a Lyapunov function $W_{9}$ such that

$$
W_{9}>0 ; \quad \dot{W}_{9}<0
$$

It must to be noticed that the reference in (16) is bounded, since it is a diffeomorphism of the dynamics $\ddot{x}_{9}$. The control input in 277 has been chosen to have a function $W_{8}$ as

$$
W_{8}=\frac{L_{8}}{2}\left(x_{8}-z_{8}\right)^{2}+\frac{1}{2 K_{8}^{\alpha}} \alpha_{8}^{2}>0
$$

such that

$$
\dot{W}_{8}=-K_{8}\left(x_{8}-z_{8}\right)^{2} \leq 0
$$

As before, Barbalat's lemma is used to show asymptotic convergence. Then, the $W_{e_{3}}$ in (48) admits a time derivative

$$
\dot{W}_{e_{3}}<0
$$

The third step of the proof is dedicated to the load part. The procedure that is used to obtain the references $z_{11}^{i}$ is the same that has been used for $z_{8}$ in (16). Let us then consider $\nu_{12}=\left[\begin{array}{ll}x_{12} & \dot{x}_{12}\end{array}\right]^{T}:$ due to the multi-time scale separation of the system, it is possible to consider the dynamics of $x_{12}$ when $x_{11}$ has already taken the value of $z_{11}$, and calculate the time 
derivative $\dot{x}_{12}$. Thus, according to the choice of the reference $z_{11}^{i}$, the subsystem $\nu_{12}$ will result linear and with a Hurwitz matrix. Indeed, with the virtual input $\dot{z}_{11}^{i}$ used to select the proper reference as in 20), it will result:

$$
\left(\begin{array}{l}
\dot{x}_{12} \\
\ddot{x}_{12}
\end{array}\right)=\left(\begin{array}{cc}
0 & 1 \\
-\bar{K}_{11} & -\underline{K}_{11}
\end{array}\right)\left(\begin{array}{l}
x_{12} \\
\dot{x}_{12}
\end{array}\right)
$$

As the system is a linear stable one, there will exist a Lyapunov function $W_{12}$ such that

$$
W_{12}>0 ; \quad \dot{W}_{12}<0
$$

As a direct consequence, the control input in (28) is chosen such that

$$
W_{11}=\frac{L_{11}}{2}\left(x_{11}-z_{11}\right)^{2}+\frac{1}{2 K_{11}^{\alpha}} \alpha_{11}^{2}>0
$$

admits a negative semidefinte time derivative, which again ensures asymptotic convergence thanks to the Barbalat's lemma utilization:

$$
\dot{W}_{11}=-K_{11}\left(x_{10}-z_{10}\right)^{2} \leq 0
$$

It is then possible to state that for both cases of CPL and CIL there exist a Lyapunov function $W_{12}$ such that the conditions in (71) are valid. As a result, the $W_{e_{4}}$ in (48) admits a time derivative

$$
\dot{W}_{e_{4}}<0
$$

The fourth part of the proof deals with the PV array stability analysis. The technique used to obtain the reference $z_{2}$ in $(15)$ is the same as for (16) and (20): for the same reasons, a Lyapunov function $W_{3}$ with as follows exists:

$$
W_{3}>0 ; \quad \dot{W}_{3}<0
$$

The choice of the control input in $(25)$ is such that the function

$$
W_{2}=\frac{L_{2}}{2}\left(x_{2}-z_{2}\right)^{2}+\frac{1}{2 K_{2}^{\alpha}} \alpha_{2}^{2}>0
$$

admits asymptotic convergence by Barbalat's lemma;

$$
\dot{W}_{2}=-K_{2}\left(x_{2}-z_{2}\right)^{2} \leq 0
$$

The multi-time scale behavior of the dynamics, which is certified by the separation principle, allows to consider the dynamics of $x_{1}$ and $x_{4}$ in their equilibrium points.

$$
\begin{gathered}
W_{1}+W_{4}=\frac{1}{2}\left(x_{1}-x_{1}^{e}\right)^{2}+\frac{1}{2}\left(x_{4}-x_{4}^{e}\right)^{2}>0 \\
\dot{W}_{1}+\dot{W}_{4}=-C_{1}\left(x_{1}-x_{1}^{e}\right)^{2}-L_{4}\left(x_{4}-x_{4}^{e}\right)^{2}<0
\end{gathered}
$$

To better remark it, please note that current $I_{P V}$ in 3 has a linear stable term. The following choice for the

$$
\dot{W}_{e_{1}} \leq 0
$$

The last part of the proof considers the control input in (26) to show stability by means of the function $W_{5}$, its time derivative $\dot{W}_{5}$ and the Barbalat's lemma:

$$
W_{5}=\frac{L_{5}}{2}\left(x_{5}-x_{5}^{*}\right)^{2}+\frac{1}{2 K_{5}^{\alpha}} \alpha_{5}^{2}>0
$$

$$
\dot{W}_{5}=-K_{5}\left(x_{5}-x_{5}^{*}\right)^{2} \leq 0
$$

Finally, the following functions show stability of the remaining dynamics, according to the considerations done for the previous case:

$$
\begin{gathered}
W_{6}+W_{7}=\frac{1}{2}\left(x_{6}-x_{6}^{e}\right)^{2}+\frac{1}{2}\left(x_{7}-x_{7}^{e}\right)^{2}>0 \\
\dot{W}_{6}+\dot{W}_{7}=-C_{6}\left(x_{6}-x_{6}^{e}\right)^{2}-L_{7}\left(x_{7}-x_{7}^{e}\right)^{2}<0
\end{gathered}
$$

Thus, the Lyapunov function in (47) ensures stability since

$$
\dot{W}_{e_{2}} \leq 0
$$

According to (46), (47), (48), (49), (50), it is then possible to state that

$$
\underline{\alpha}(|e|) \leq W(e) \leq \bar{\alpha}(|e|)
$$

where the functions $\bar{\alpha}, \underline{\alpha} \in K_{\infty}$. Furthermore, from the conditions in (61), 697, (74), 80) and (85), it follows that there exist functions $\bar{\beta}, \bar{\gamma} \in K_{\infty}$ such that the following inequality holds, ensuring ISS:

$$
\begin{aligned}
\dot{W}\left(e, x_{13}^{*}\right) & =\dot{W}_{1,3}+\dot{W}_{4,6}+\dot{W}_{7,9}+\dot{W}_{8,10}+\dot{W}_{2,5,11} \\
& \leq-\bar{\beta}(|e|)+\bar{\gamma}\left(\left|x_{11}^{*}\right|\right)
\end{aligned}
$$

The composite Lyapunov function $W$ in (45) results to be an ISS-like Lyapunov function, where the equilibrium point $x_{13}^{*}$ can be considered as a fictitious input. Consequently, inequality (44) follows from equation (87).

Theorem 1 and the related proof state that the provided controllers locally stabilize the grid in (11), since the stability analysis provided for the extended state $e$ is directly applied to the original state $x$. The constructive proof introduces the possibility to easily increase the size of the system by adding physical devices. Indeed, stability analysis can still be performed with the same methods, including the possibility of Plug\&Play devices [22]. For example, in case of addition of a PV panel, a battery or a load, their stability analysis will be performed with the same functions $W_{e_{1}}, W_{e_{2}}$ and $W_{e_{4}}$, respectively. Obviously, Kirchoff's law considerations will drive to modifications on the reference $z_{10}$. On the same way, several supercapacitors will modify such reference as well, to share the duty among the different $W_{e_{3}}$. Again Kirchoff's law considerations will drive to a different description of the interconnections with the DC bus in case of multiple AC/DC devices. Nevertheless, the adopted constructive technique which has been used for finding the control inputs and the references can be easily adapted.

\section{Simulations}

As already described, the main control target of the model of the DC MicroGrid in Figure 5 is to provide ancillary services to the AC grid, in particular, to help in the frequency control at AC side. The parameters of the grid are introduced in Table I The simulations are carried out in Matlab environment supposing 5 minutes grid operation and two different types of loads, considering constant impedance load (CIL, pure resistive) and constant power load (CPL). Along the 5 minutes simulations, the following events are considered: a) in $\mathrm{AC}$ generators, the 
equilibrium between the electric torque and mechanical torque suddenly changes for $t=20 \mathrm{~s}$ and $t=150 \mathrm{~s}$ affecting the frequency in the $\mathrm{AC}$ side, $\mathrm{b}$ ) the voltage reference for the $\mathrm{DC}$ grid varies every 30 seconds (given by a higher controller) and c) the battery manager system (BMS) receives new references every 10 seconds.

TABLE I

PARAMETERS

\begin{tabular}{|c|c|c|c|c|c|}
\hline$R_{\text {load }}$ & $C_{1}$ & $L_{2}$ & $C_{3}$ & $L_{4}$ & $R_{4}$ \\
\hline $1 \div 20 \Omega$ & $10 \mathrm{mF}$ & $20 \mathrm{mH}$ & $4 \mathrm{mF}$ & $2 \mathrm{mH}$ & $25 \mathrm{~m} \Omega$ \\
\hline$L_{5}$ & $R_{5}$ & $C_{6}$ & $L_{7}$ & $R_{7}$ & $L_{8}$ \\
\hline $10 \mathrm{mF}$ & $12.5 \mathrm{~m} \Omega$ & $4 \mathrm{mF}$ & $1 \mathrm{mH}$ & $10 \mathrm{~m} \Omega$ & $1 \mathrm{mH}$ \\
\hline$R_{8}$ & $C_{9}$ & $L_{10}$ & $R_{10}$ & $L_{11}$ & $R_{10}$ \\
\hline $1 \mathrm{~m} \Omega$ & $4 \mathrm{mF}$ & $1 \mathrm{mH}$ & $14 \mathrm{~m} \Omega$ & $5 \mathrm{mH}$ & $30 \mathrm{~m} \Omega$ \\
\hline$C_{12}$ & $C_{13}$ & $L_{a c}$ & $R_{a c}$ & $l$ & $r$ \\
\hline $4 \mathrm{mF}$ & $10 \mathrm{mF}$ & $5 \mathrm{mH}$ & $62.5 \mathrm{~m} \Omega$ & $100 \mathrm{mH}$ & $0.3 \Omega$ \\
\hline \multicolumn{5}{|c|}{ DC grid nominal voltage } & $800 \mathrm{~V}$ \\
\hline \multicolumn{5}{|c|}{ PV nominal voltage } & $400 \mathrm{~V}$ \\
\hline \multicolumn{5}{|c|}{ AC grid nominal voltage } & $230 \mathrm{~V}$ \\
\hline \multicolumn{5}{|c|}{ Frequency } & $50 \mathrm{~Hz}$ \\
\hline
\end{tabular}

\section{A. Frequency support with CILs}

In Figure 6 the power injected by the solar panels, the power consumed by the DC load (constant impedance), and the power provided/absorbed by the battery and supercapacitors are exhibited. We can observe as the battery follows its reference given by a higher level controller each $10 \mathrm{~s}$.

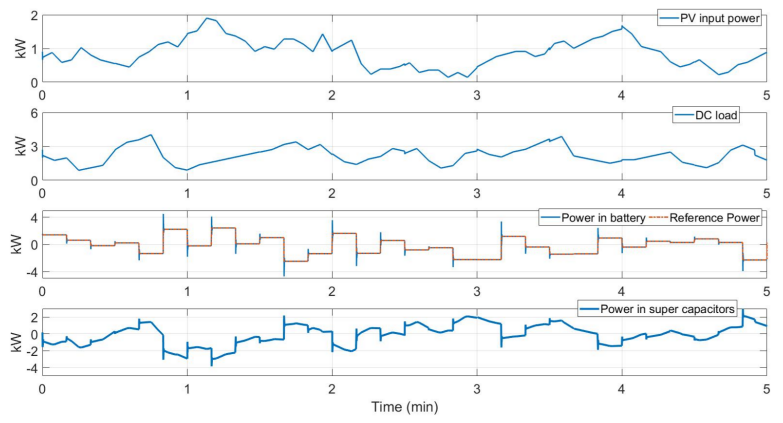

Fig. 6. The powers in the DC side.

In Figure 7 a comparison between a Proportional Integral (PI) controller and the proposed one for frequency control in the AC side is exhibited. We can observe that in both cases the frequency tracks its reference, but the PI controller has slower performances. This is important and has to be remarked, since the fast stabilization of frequency is vital for the proper operation of the AC/DC converter, and both control philosophies depends on the knowledge of this variable (by means of Phase lock loop technique or similar). In order to do a fair comparison, the PI has been initialized with the nominal value and it was then tuned following classical criteria.

Figure 8 shows the AC current in a phase both for the proposed controller and for the PI. We can appreciate as the current achieves the steady state faster with the non-linear control.

In figure 9 the DC bus voltage is shown. We can observe that the voltage successfully tracks its reference for the whole considered period, and it is always in a range of $10 \%$ with respect to the nominal value, in concordance with the grid
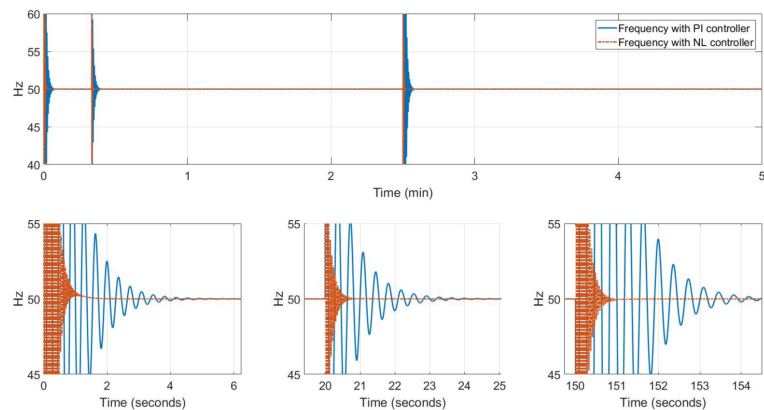

Fig. 7. The frequency variation in the $\mathrm{AC}$ side.

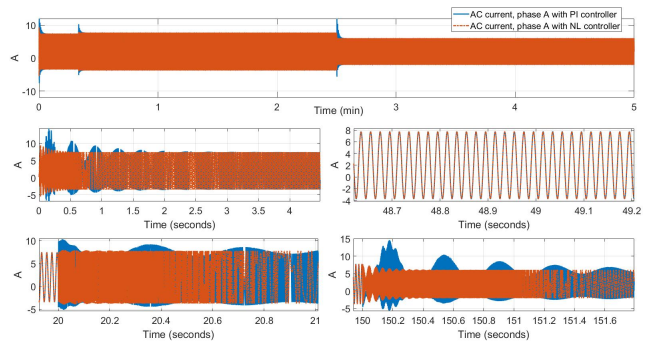

Fig. 8. The AC currents.

code for DC grids [39]. The reference is given by a higher controller, which is not studied in this paper, but it is supposed to always guarantee the energy balance of the system, in order to ensure stability [25], [26]
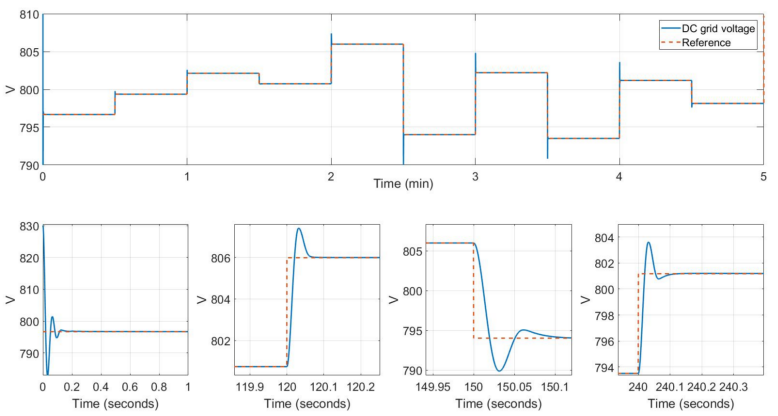

Fig. 9. The DC bus voltage dynamic.

Finally, in Figure 10, both the stored energies of battery and supercapacitor are shown. In both cases the final energy is less than the initial one. This fact must not surprise us, because the DC MicroGrid provides the required energy to restore the frequency in the $\mathrm{AC}$ side.

\section{B. Frequency support with CPLs}

In Figure 11 the power injected by the solar panels, the power consumed by the DC load (CPL), and the power provided/absorbed by the battery and super capacitors are exhibited. The CPL changes its power reference each $60 \mathrm{~s}$. We can appreciate as the results both for the battery and supercapacitors are different due to the presence of the CPL, and consequently the higher controller gives different references. 
1

2

3

4

5

6

7

8

9
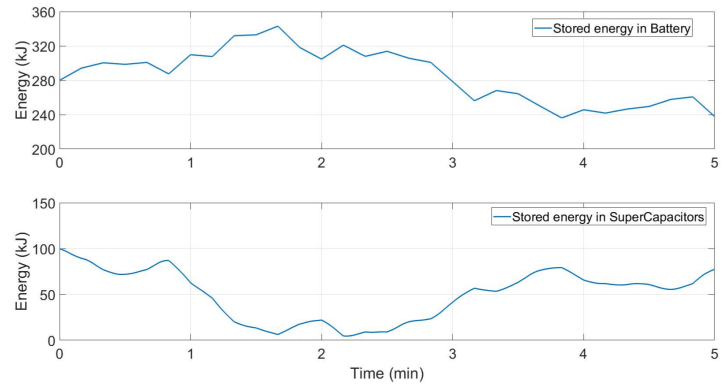

Fig. 10. The stored energy in battery and supercapacitor.

On the other hand, the power injected by the solar panels are the same as the previous case.

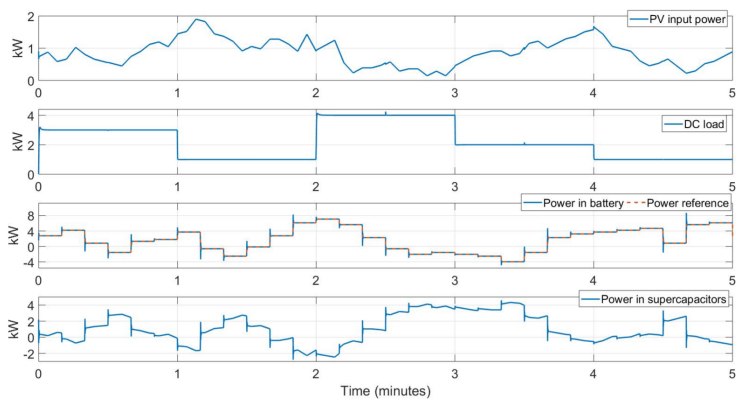

Fig. 11. The powers in DC side with CPL.

In figure 12 the frequency in the AC side is shown. We can observe as the proposed nonlinear controller produces a faster frequency support than the PI also in case of CPLs.

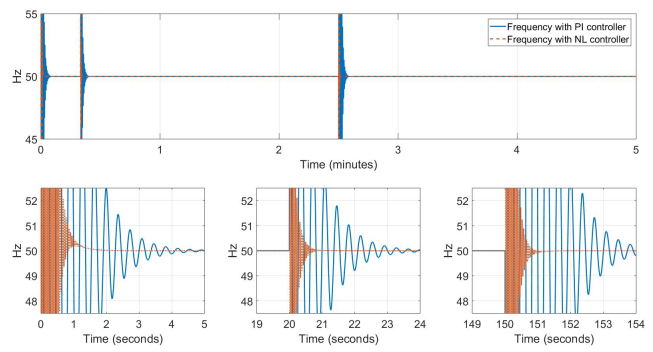

Fig. 12. The variation of frequency in the AC side with CPL.

In figure 13 the DC bus voltage is shown. We can observe how the voltage tracks its reference while being always in a range of $10 \%$ with respect to the nominal value, in concordance with the grid code for DC grids.

In figure 14 the voltage and the current for the CPL are shown. We can observe as although these values are affected by the change of reference in the DC grid voltage (each $30 \mathrm{~s}$ while the CPL power reference varies each $60 \mathrm{~s}$ ), the nonlinear control stabilizes both the voltage and the current in the load. Besides, we can observe as the variations in the AC generators $(t=20 \mathrm{~s}$ and $t=150 \mathrm{~s}$ ) have a not significant impact in the CPL voltage and current.

Finally, in figure 15 the trajectories of the load curves for different time are shown. We can appreciate as the trajectories
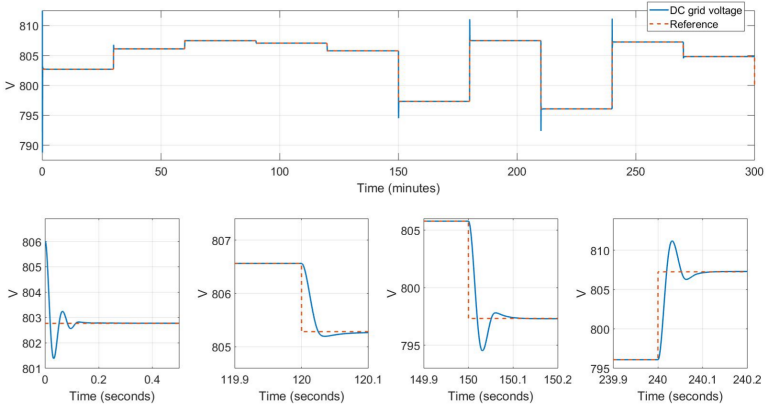

Fig. 13. The DC bus voltage dynamic with CPL.
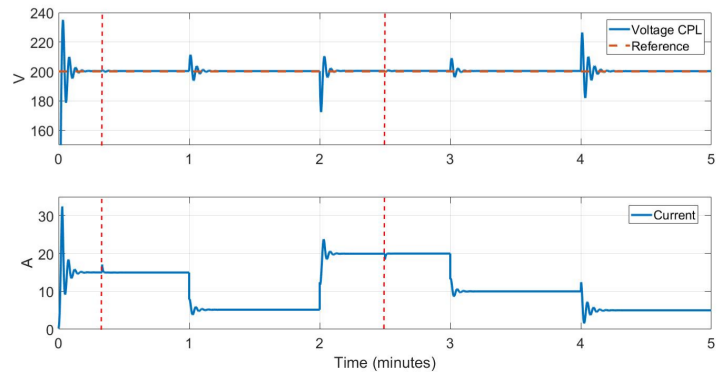

Fig. 14. The voltage and current in the CPL.

goes to the operation points accordig to each power and voltage levels, and in concordance with Figures 14 and 11 p.

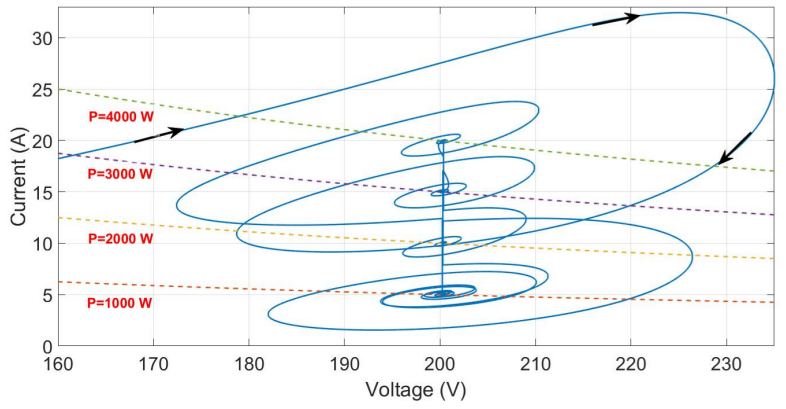

Fig. 15. The V-I trajectories in the CPL case.

\section{CONCLUSION}

This paper provides an ISS-Lyapunov based nonlinear control approach for DC MicroGrids considering Plug\&Play philosophy. The main target of providing frequency support to AC grid while keeping DC grid stability is successfully reached. Besides, a new nonlinear approach for CPL based on backstepping technique is addressed.

The simulations results show how the proposed controllers offer better performance with respect to classical PI, which is a significant improvement for DC distributed MicroGrids, specially if networks with a high penetration of renewable energy resources and storage devices are involved. In addition, these type of networks usually operates with nonlinear elements, as CPL, and the proposed control fits better than classical ones.

Future works will address voltage support for AC grids, power quality restrictions as well as more sophisticated converter topologies. 


\section{REFERENCES}

[1] M. A. Eltawil and Z. Zhao, "Grid-connected photovoltaic power systems: Technical and potential problems. A review," Renewable and Sustainable Energy Reviews, vol. 14, no. 1, pp. 112 - 129, 2010.

[2] P. Piagi and R. Lasseter, "Autonomous control of microgrids," in Power Engineering Society General Meeting, 2006. IEEE, 2006, pp. 8 pp.-.

[3] N. Hatziargyriou, H. Asano, R. Iravani, and C. Marnay, "Microgrids," Power and Energy Magazine, IEEE, vol. 5, no. 4, pp. 78-94, July 2007.

[4] J. Guerrero, P. C. Loh, T.-L. Lee, and M. Chandorkar, "Advanced Control Architectures for Intelligent Microgrids Part II: Power Quality, Energy Storage, and AC/DC Microgrids," Industrial Electronics, IEEE Transactions on, vol. 60, no. 4, pp. 1263-1270, April 2013.

[5] L. E. Zubieta, "Are microgrids the future of energy?: DC microgrids from concept to demonstration to deployment," IEEE Electrification Magazine, vol. 4, no. 2, pp. 37-44, June 2016.

[6] J. Barton and D. Infield, "Energy storage and its use with intermittent renewable energy," Energy Conversion, IEEE Transactions on, vol. 19, no. 2, pp. 441-448, June 2004.

[7] G. Krajačić, N. Duić, Z. Zmijarević, B. V. Mathiesen, A. A. Vučinić, and M. da Graça Carvalho, "Planning for a $100 \%$ independent energy system based on smart energy storage for integration of renewables and $\mathrm{CO}_{2}$ emissions reduction," Applied Thermal Engineering, vol. 31, no. 13, pp. 2073 - 2083, 2011.

[8] H. Farhangi, "The path of the smart grid," Power and Energy Magazine, IEEE, vol. 8, no. 1, pp. 18-28, January 2010.

[9] R. H. Lasseter, "Microgrids And Distributed Generation," Intelligent Automation and Soft Computing, vol. 16, no. 2, pp. 225-234, 2010.

[10] Network Code on Load-Frequency Control and Reserves, ENTSO-E AISBL, 2013.

[11] J. R. Lima, "Variable speed pumped storage plants multi-time scale control to allow its use to power system stability," Ph.D. dissertation, Université Paris-Saclay, 2017.

[12] Y. G. Rebours, D. S. Kirschen, M. Trotignon, and S. Rossignol, "A Survey of Frequency and Voltage Control Ancillary Services - Part I: Technical Features," IEEE Transactions on Power Systems, vol. 22, no. 1, pp. $350-357,2007$.

[13] A. Iovine, S. B. Siad, G. Damm, E. De Santis, and M. D. Di Benedetto, "Nonlinear Control of a DC MicroGrid for the Integration of Photovoltaic Panels," IEEE Transactions on Automation Science and Engineering, vol. 14, no. 2, pp. 524-535, April 2017.

[14] R. F. Bastos, T. Dragicevic, J. M. Guerrero, and R. Q. Machado, "Decentralized control for renewable DC Microgrid with composite energy storage system and UC voltage restoration connected to the grid," in IECON 2016 - 42nd Annual Conference of the IEEE Industrial Electronics Society, Oct 2016, pp. 2016-2021.

[15] L. Meng, Q. Shafiee, G. F. Trecate, H. Karimi, D. Fulwani, X. Lu, and J. M. Guerrero, "Review on control of dc microgrids and multiple microgrid clusters," IEEE Journal of Emerging and Selected Topics in Power Electronics, vol. 5, no. 3, pp. 928-948, Sept 2017.

[16] M. Jiménez Carrizosa, "Hierarchical control scheme for multi-terminal high voltage direct current power networks," Ph.D. dissertation, $\mathrm{PhD}$ report, Université Paris-Sud, 2015.

[17] M. Jiménez Carrizosa, A. Arzandé, F. D. Navas, G. Damm, and J. C. Vannier, "A control strategy for multi-terminal dc grids with renewable production and storage devices," IEEE Transactions on Sustainable Energy, vol. PP, no. 99, pp. 1-1, 2017.

[18] T. Dragicevic, J. Vasquez, J. Guerrero, and D. Skrlec, "Advanced LVDC Electrical Power Architectures and Microgrids: A step toward a new generation of power distribution networks." Electrification Magazine, IEEE, vol. 2, no. 1, pp. 54-65, March 2014.

[19] A. H. Etemadi, E. J. Davison, and R. Iravani, "A generalized decentralized robust control of islanded microgrids," IEEE Transactions on Power Systems, vol. 29, no. 6, pp. 3102-3113, Nov 2014.

[20] Q. Xu, C. Zhang, C. Wen, and P. Wang, "A novel composite nonlinear controller for stabilization of constant power load in de microgrid," IEEE Transactions on Smart Grid, vol. PP, no. 99, pp. 1-1, 2017.

[21] T. L. Vu and K. Turitsyn, "A framework for robust assessment of power grid stability and resiliency," IEEE Transactions on Automatic Control, vol. 62, no. 3, pp. 1165-1177, March 2017.

[22] M. Tucci, S. Riverso, and G. Ferrari-Trecate, "Line-independent plugand-play controllers for voltage stabilization in dc microgrids," IEEE Transactions on Control Systems Technology, vol. PP, no. 99, pp. 1-9, 2017.

[23] A. A. A. Radwan and Y. A. R. I. Mohamed, "Networked control and power management of ac/dc hybrid microgrids," IEEE Systems Journal, vol. 11, no. 3, pp. 1662-1673, 2017.
[24] B. Liu, F. Zhuo, Y. Zhu, and H. Yi, "System operation and energy management of a renewable energy-based dc micro-grid for high penetration depth application," IEEE Transactions on Smart Grid, vol. 6, no. 3, pp. $1147-1155,2015$.

[25] M. Jiménez Carrizosa, F. D. Navas, G. Damm, and F. LamnabhiLagarrigue, "Optimal power flow in multi-terminal HVDC grids with offshore wind farms and storage devices," International Journal of Electrical Power and Energy Systems, vol. 65, pp. 291 - 298, 2015.

[26] A. Iovine, T. Rigaut, G. Damm, E. De Santis, and M. D. Di Benedetto, "Power Management for a DC MicroGrid integrating Renewables and Storages," submitted to Control Engineering Practice, https://drive.google.com/file/d/1jtisxtK7VX5WK0iK8GbUtXZkwEYVDLB/view? usp=sharing.

[27] P. Kundur, J. Paserba, V. Ajjarapu, G. Andersson, A. Bose, C. Canizares, N. Hatziargyriou, D. Hill, A. Stankovic, C. Taylor, T. Van Cutsem, and V. Vittal, "Definition and classification of power system stability IEEE/CIGRE joint task force on stability terms and definitions," Power Systems, IEEE Transactions on, vol. 19, no. 3, Aug 2004.

[28] A. Iovine, S. B. Siad, G. Damm, E. De Santis, and M. D. Di Benedetto, "Nonlinear control of an AC-connected DC microgrid," in Industrial Electronics Society, IECON 2016 - 42nd Annual Conference of the IEEE, 24-27 October 2016.

[29] J. A. Solsona, S. G. Jorge, and C. A. Busada, "Nonlinear control of a buck converter which feeds a constant power load," IEEE Transactions on Power Electronics, vol. 30, no. 12, pp. 7193-7201, 2015.

[30] L. Benadero, R. Cristiano, D. J. Pagano, and E. Ponce, "Nonlinear analysis of interconnected power converters: A case study," IEEE Journal on Emerging and Selected Topics in Circuits and Systems, vol. 5, no. 3, pp. 326-335, Sept 2015.

[31] H. K. Khalil and J. Grizzle, Nonlinear systems. Prentice hall New Jersey, 1996, vol. 3.

[32] B. Charlet, J. Lvine, and R. Marino, "On dynamic feedback linearization," Systems and Control Letters, vol. 13, no. 2, pp. 143-151, 1989.

[33] E. D. Sontag, Input to State Stability: Basic Concepts and Results. Berlin, Heidelberg: Springer Berlin Heidelberg, 2008, pp. 163-220. [Online]. Available: http://dx.doi.org/10.1007/978-3-540-77653-6_3

[34] P. Kundur, N. J. Balu, and M. G. Lauby, Power system stability and control. McGraw-Hill, 1994.

[35] A. B. Jusoh, "The instability effect of constant power loads," in PECon 2004. Proceedings. National Power and Energy Conference, 2004., Nov 2004, pp. $175-179$.

[36] A. Bindra, "Pulsewidth modulated controller integrated circuit: Four decades of progress [a look back]," Power Electronics Magazine, IEEE, vol. 1, no. 3, pp. 10-44, Sept 2014.

[37] P. Kundur, Power systems stability and control, 1st ed. Mc Graw Hill, 1993.

[38] E. Hossain, R. Perez, A. Nasiri, and S. Padmanaban, "A comprehensive review on constant power loads compensation techniques," IEEE Access, pp. 1-1, 2018.

[39] ENTSO-E Draft Network Code on High Voltage Direct Current Connections and DC-connected connected Power Park Modules, ENTSO-E AISBL, 2014 